\title{
O RITUAL E A BRINCADEIRA: RIVALIDADE E AFEIÇÃO NO BUMBÁ DE PARINTINS, AMAZONAS*
}

\author{
Maria Laura Viveiros de Castro Cavalcanti
}

Gostaria de começar com um trecho da Epopeia de Gilgamesh, um texto do terceiro milênio antes de Cristo, oriundo da antiga Mesopotâmia. Nele, o herói Gilgamesh, poderoso como os deuses mas mortal como os homens, sai em busca do elixir da eterna juventude. Depois de atravessar a escuridão de uma montanha profunda, ele encontra a jovem Siduri, que lhe diz: "Gilgamesh, em busca do que tanto corres? Jamais encontrarás essa vida que tanto procuras. Quando os deuses criaram o homem, eles lhe dedicaram a morte e retiveram essa vida para si. Quanto a ti, Gilgamesh, trate de comer boas coisas; dia e noite, noite e dia, dance e alegre-se, festeje e rejubile-se. Tenha sempre roupas limpas, banhe-se em águas frescas, queira bem à criança que segura tua mão, faça tua mulher feliz com teu enlace; pois isto, Gilgamesh, também é parte do que coube ao homem" (The epic of Gilgamesh 2006:43, trad. minha).

$\mathrm{Na}$ antropologia, a finitude trazida pela morte e o celebrar, dançar, alegrar-se e acalentar caras afeições foram acolhidos e tematizados nos estudos dos rituais. No Espiritismo Kardecista, tema de minha primeira pesquisa antropológica (Cavalcanti 1983), a primeira parte do lote atribuído aos homens indicada na Epopeia é o foco em torno do qual giram a cosmologia, o sistema ritual e a noção da pessoa espírita em um monumental empenho de negação, que bane do vocabulário religioso a própria palavra "morte". A segunda parte do "lote humano" é especialmente marcante em rituais festivos a que dediquei minhas pesquisas posteriores, como o Carnaval carioca, com a celebração do corpo e da carne (Cavalcanti 2006a, 2015), e o Bumbá de Parintins, com a celebração da rivalidade e das afeições (Cavalcanti 2000, 2002, 2006b).

Neste texto, após breve incursão pelo estudo antropológico dos rituais, busco elaborar aspectos etnográficos da dança festiva do Bumbá de Parintins que falam dessa dimensão celebratória, tão vital da nossa experiência coletiva. Trata-se de enfocar a associação, iluminada pela noção de ritual, entre os afetos e a expressão obrigatória dos sentimentos e a experiência 
social dos grupos envolvidos na produção anual do festival. A noção de ritual, apreendida etnograficamente, conduz a análise da acentuada rivalidade entre os dois grupos de Bumbás que emerge como uma dimensão marcante para a compreensão do festival. Essa rivalidade, por sua vez, é enfocada como uma produção ritual contínua. Nessa produção, a noção nativa de brincadeira ganha destaque como laço a unir os dados etnográficos à elaboração conceitual dessa mesma noção - brincadeira - em um patamar analítico que traz consigo o tema da ambivalência tão característico das trocas agonísticas.

Veremos como a história do festival de Parintins se entrelaça com alterações importantes no traçado urbano local que definiram o cenário atual, que tem como marco a inauguração de sua arena festiva, o popular Bumbódromo, em 1988. Enfocaremos a preparação festiva que engendra, a partir de inúmeros mecanismos de ritualização, como tabus, evitações, provocações e confrontos, a crescente rivalidade entre os dois grupos brincantes. Essa rivalidade se transmuta finalmente em expressão artística plena nas apresentações dos dois grupos que se alternam na arena nas três noites do último fim de semana de junho. Ali, o almejado esplendor das performances é estimulado pelo desejo obsessivo de superação e derrota do "contrário". O argumento se conclui com a análise do trabalho do rito que, ao produzir abertamente a exacerbação da rivalidade, promove mais silenciosamente a necessária complementariedade e o reconhecimento pleno do outro que funda a possibilidade da brincadeira e a torna uma experiência real no ritual festivo ${ }^{1}$.

\section{O estudo antropológico dos rituais}

Na tradição antropológica, a noção de ritual articula valiosos estudos etnográficos a expressiva produção conceitual. Integrando a própria formação da disciplina, tais estudos nos levam a um dos aspectos centrais de sua singularidade: a busca de elucidação da natureza simbólica da ação humana, sempre concreta e muito variada. Por esta razão, com seus diferentes enfoques, os estudos de ritual convergem para visões gerais da cultura e da vida social.

A relevância da noção de ritual é notável nas obras seminais de James Frazer (1981 [1890]), Edward B. Tylor (1970 [1871]) e Robertson Smith (2005 [1894]). Em especial, o fecundo livro de Émile Durkheim, As formas elementares da vida religiosa (1996 [1912]), situado no contexto do empreendimento coletivo da Escola Sociológica Francesa, renovou a abordagem da vida social 
e por extensão dos rituais, tão estreita foi a conexão estabelecida pelo autor entre os dois temas. É possível dizer que as muitas conceituações antropológicas de ritual que se seguiram vicejaram sob o profícuo guarda-chuva durkheimiano (Skoruspki 1983). Abriu-se então um enfoque conceitual abrangente e inovador cujos desdobramentos se ramificaram nas obras de inúmeros autores ${ }^{2}$.

Nesses estudos, cheios de entrelaçamentos, distintas ênfases conceituais permitem distinguir certos núcleos teóricos, pois rituais ora representam, ora performam, ou comunicam, ou conhecem, metacomunicam, transformam, memorizam, dramatizam, teatralizam. O conceito de metacomunicação, por exemplo, ganha especial densidade com Gregory Bateson (2008, 1972); e aquele de comunicação emerge particularmente nítido em Edmund Leach $(1995,1978)$. Michel de Leiris, por sua vez, explorou de modo fascinante a ideia da teatralização (Leiris 1989), e empreendeu um belo ensaio expressivo-conceitual sobre a tauromaquia compreendida como ritual (Leiris 2001). Com outros contornos, mais próximo da ideia da dramatização, o conceito de teatralização aparece de modo notável também em Geertz (1980). Vale lembrar que a metáfora conceitual do teatro, por sinal, foi utilizada com êxito por Hilda Kuper (2014 [1944]) para descrever o ritual da realeza entre os suazi no estudo que inspirou Gluckman (1974), que a ela sobrepôs a noção psicanalítica de catarse.

Drama, por sua vez, é uma noção que se desdobra por toda a obra de Victor Turner, que tem o ritual como um elemento central, desembocando na noção de performance (Cavalcanti 2008, 2013). A noção turneriana de performance, entretanto, difere em muito do performativo austiniano (Austin 1962) tal como elaborado por Stanley Tambiah (1985) (ver Peirano 2001), ou mesmo da ideia mais artística de performance elaborada por Bauman (1977), a qual se abre, por sua vez, para toda a discussão da oralidade (Zumthor 1972). A noção de performance tal como elaborada por Victor Turner enfatiza a dimensão da experiência entendida processualmente (Dawsey 2005). E é preciso lembrar que a ideia do ritual como operador de transformações decididamente incorporada na abordagem turneriana do ritual, em especial na formulação do conceito de símbolo ritual (Turner 2005a) e associada ao aspecto transicional (Turner 2005b) - está posta na obra clássica de Van Gennep (2011 [1909]). A dimensão cognitiva dos rituais, por sua vez, se evidencia no trabalho de Valeri (1985), e a articulação do ritual a dispositivos mnemônicos é elaborada por Severi (2007). O campo de estudos é amplo e esses conceitos diversos, sempre analógicos, que buscam elucidar as formas da simbolização ritual bem atestam os inúmeros desdobramentos teóricos do assunto. 
Meu ponto de partida é uma noção etnográfica de ritual, pois embora o conteúdo da distinção entre "ritual" e "não ritual" varie amplamente, não há grupo humano que não a faça, assim demarcando, como observou Roberto DaMatta (1979), tempos e espaços extraordinários em contraponto a dimensões cotidianas da vida coletiva. Desse modo, os rituais articulam, desarticulam e rearticulam permanentemente elementos díspares oriundos da experiência social apreendida sob múltiplos ângulos. Nessa direção, Valério Valeri (1994) refere-se aos rituais, de modo bastante feliz, como agregados simbólicos de condutas, experiências e ações. Tal perspectiva, ao enfatizar a conexão sempre muito viva dos rituais com a experiência social, valoriza sua dinâmica e considera suas inconsistências e falhas.

No cerne de todos esses estudos, entretanto, estamos sempre diante do problema de como entender a ação humana: o ato, o gesto, o corpo e o sentido de suas muitas expressões. Embora a linguagem verbal tenha aqui obviamente seu lugar, com os rituais vemo-nos, de modo particularmente nítido, diante de formas não verbais de pensamento que, situadas aquém ou além da palavra, substituem-na ou a ela se sobrepõem. Com os sentidos corporais apreendemos então o mundo por meio de múltiplas formas expressivas.

Evans Pritchard (2005 [1976]) ressaltou a integração entre a corporalidade da dança e o ritmo da música ao descrever admiravelmente o adivinho zande que dança a pergunta que lhe é feita. Merleau-Ponty (1964) iluminou o olhar sinestésico, integrante da experiência corporal plena, ao refletir sobre a pintura de Cézanne. O corpo, nos ensinou Marcel Mauss (2003b), é o instrumento humano primordial não do qual falamos mas com o qual falamos.

"O que um povo faz em relação a seus deuses deve ser um caminho, e talvez o mais seguro, para o que ele pensa", dizia, em 1903, Jane Harrison em seu estudo da religião grega na época clássica (Harrison 1908). Harrison é evocada por Victor Turner em Floresta de símbolos (Turner 2005). Em "Os símbolos no ritual Ndembu", ensaio que abre o livro, publicado originalmente em 1965, o autor conceituou de modo mais acabado sua abordagem dos rituais, reivindicando mais assumidamente do que a maioria dos demais autores a visão durkheimiana que emerge no capítulo VII do livro II de As formas elementares da vida religiosa (Durkheim 1996 [1912). Nesse viés da argumentação durkheimiana, não há distinção entre a ordem social e sua reapresentação simbólica. O ritual é pensado como um verdadeiro dínamo, centro ativo e criativo da vida social. Intensificação sensorial é uma ideia-chave, e é no âmago da experiência ritual que a autoconsciência da vinculação social emerge, transfigurada em representações coletivas. A "sociedade", afinal, é "delírio bem fundado", instaurada pela autoconsciência 
do grupo, uma consciência indireta e possível apenas por meio dos símbolos. Victor Turner fez derivar dessa visão não uma teoria sistemática do ritual e nem definições abrangentes dessa noção, mas antes uma notável apreensão do sentido do vivido (Cavalcanti 2008, 2012b, 2013). Indo direto ao ponto, uma notável apreensão do lugar da afetividade nos processos rituais.

Afetividade compreendida como o mundo dos afetos, um mundo onde as nuances são fundamentais e nem sempre claras. Como diz André Green em O discurso vivo (1982), afetividade é "um termo categorial que agrupa todos os aspectos subjetivos que qualificam a vida emocional em sentido amplo", um termo "mais metapsicológico do que descritivo". Entendo-a aqui como designando a dimensão da experiência humana que está aquém da linguagem verbal, e mesmo da expressão das emoções e dos sentimentos que dão graça e calor aos processos de vinculação social, com o que entramos mais claramente no terreno antropológico das classificações sociais vislumbrado por Marcel Mauss em seu clássico "A expressão obrigatória dos sentimentos" (Mauss 2009 [1921]).

Essa dimensão afetiva da experiência social se faz presente de modo notável na obra de Victor Turner não só no pathos de seu estilo, que interpela a compaixão do leitor, mas também, especialmente, na conceituação do símbolo ritual. Graças a ela, Turner nos trouxe também, em "Betwix, between", ensaio integrante do mesmo livro (Turner 2005b), o adensamento do formidável conceito de rito de passagem proposto por Van Gennep em 1909. A abordagem processual do ritual define-se nitidamente junto com o foco na liminaridade, cuja riqueza simbólica ampara a possibilidade de transformação subjetiva e intersubjetiva, apoiada por sua vez na valorização da experiência, uma noção cuja fundamentação filosófica Turner encontraria em Wilhem Dilthey (2010). A experiência vivida integra a corporalidade e a materialidade aos processos de apreensão de múltiplos sentidos condensados nos símbolos e torna-se, por isso, acessível à compreensão.

Também Gregory Bateson, em Naven (2008 [1936]), buscou como conceituar, e com isso transmitir não só a qualidade intelectual e cognitiva, o eidos da vida social dos iatmul, como seu ethos, sua qualidade emocional. Os trabalhos de Turner e de Bateson não definem exclusividades teóricas a serem seguidas. São para mim afinidades eletivas e fontes de inspiração, pois o que há de mais marcante no Bumbá de Parintins é a celebração da rivalidade, como formulou de modo feliz o pesquisador Andréas Valentin (2005).

E eu acrescentaria mais amplamente a celebração das afeições, pois os sentimentos de antipatia, animosidade e mesmo de hostilidade devotados ao Boi contrário associam-se inextrincavelmente ao grande carinho, amor e mesmo devoção ao próprio Boi. 


\section{"Isso é brincadeira!"}

O Festival dos Bois Bumbás de Parintins, Amazonas, no qual os dois grupos de Bois se apresentam, acontece atualmente nas três noites do último fim de semana de junho. Parintins tem cerca de 100.000 habitantes, e fica na ponta de uma das ilhas do arquipélago das Tupinambaranas, no médio rio Amazonas, bem próxima à fronteira com o Pará3. Se um forasteiro lá chegar em pleno ambiente festivo, como ocorreu comigo nos idos de 1996, logo experimentará uma insólita pressão para adesão a um ou outro Boi e se verá sutil ou explicitamente constrangido à observância dos inúmeros tabus que regulam a relação entre, e a circulação por entre, os dois Bois de Parintins. Devo admitir que, de fato, é difícil compreender o Bumbá sem se deixar envolver pela pressão de adesão a um dos Bois" ${ }^{4}$. O mundo do "brincar de boi" é feito de afeições intensas: é preciso escolher para pertencer ao todo festivo instituído pela própria brincadeira.

O tema da rivalidade na troca social - a ambivalência do dom iluminada por Marcel Mauss no "Ensaio sobre a dádiva" (2003a [1923-24]), associada à relevância da competição e do conflito como formulou Georg Simmel em "Formas da interação social" (1971) - já emergira em meu trabalho com o carnaval carioca (Cavalcanti 2006a). Sua presença é marcante em inúmeros circuitos da cultura popular contemporânea, onde rivalizar - de modo explícito, assumido, por vezes institucionalizado na forma dos desfiles e concursos, ou mesmo em formas mais sutis e caladas - é parte fundamental da graça, e mesmo do risco ou do perigo, daquilo que se faz.

Também nesses circuitos festivos, como nos lembra Gumbrecht (2006) em sua reflexão sobre a natureza cultural das competições esportivas, essa rivalidade - o agon - associa-se ao arete - o "dar o melhor de si". Com a diferença de que, no ambiente festivo popular, esse dar o melhor de si assume a forma de múltiplas expressões artísticas; há sempre canto, música, muita dança e artes plásticas e visuais em cena. Em Parintins, esse confronto festivo, mediado pela performance artística e expressiva diante do outro opositor, está na raiz da categoria nativa com a qual seus participantes se referem ao que fazem: brincadeira, termo que integra o Bumbá a um amplo conjunto de expressões populares envoltas num ambiente de lazer, jogo, diversão, teatro e festa ${ }^{5}$. Brincadeiras de gente grande, que insistem em retornar no tempo e propiciam a continuidade da própria experiência de ser e de pertencer aos grupos que as promovem e mesmo a coletividades mais amplas. Em Parintins tudo isso se expressa de modo muito peculiar, pois o confronto, que acontece entre apenas dois contendores, se exacerba: se sou Caprichoso, Garantido é meu contrário, meu não ser, do qual, entretanto, dependo profundamente 
para "brincar de boi". Essa proximidade da intimidade com a hostilidade, essa modulação da rivalidade pela necessidade da colaboração, essa repulsa que, no entanto, interpela sempre o contrário, é o que há de mais característico e intrigante no ambiente festivo do Bumbá de Parintins.

Não se trata, assim, apenas de reconhecer que adentramos um universo mítico e ritual onde, como nos ensinou Jean Pierre Vernant (2001), a distinção entre a crença e a consciência da natureza ficcional daquilo em que se crê é irrelevante $^{6}$. Do ponto de vista analítico, brincadeira é também um conceito-chave a qualificar a experiência vivida, situada num lugar inteiramente ficcional. Brincadeira, no sentido proposto por Gregory Bateson (1972), como uma moldura metacomunicativa peculiar na qual aquilo que é denotado por um gesto ou ato - no exemplo de Bateson, uma mordida - não só não denota aquilo que denota, como nos projeta num ambiente eminentemente criativo. Pois a "mordida-que-não-é-mordida", ao substituir a mordida ausente à qual alude, torna esta igualmente uma criação puramente ficcional. Brincadeira também no sentido concebido por Donald Winnicott (1975), experiência ligada aos fenômenos transicionais situados no "entre", um lugar que não é nem o psicossoma (a unidade individual formada pelo corpo unido ao psiquismo), nem a experiência objetiva do mundo; lugar daquilo que, embora estando fora de mim, não é exatamente o mundo externo. Um lugar intersubjetivo, de compartilhamento e superposições de atenções onde viceja a experiência cultural criativa. Lugar privilegiado, nos diria Victor Turner (2005), para a proliferação de símbolos culturais.

\section{Simbolizando}

A interjeição "Bumba, meu-boi!" sintetiza a ação simbólica pública e dramática dos grupos de brincantes em torno de um artefato dançante (uma carcaça feita das mais diversas maneiras dentro da qual se insere um brincante), e se desdobra nos múltiplos nomes da brincadeira, que se espraiou pelo país desde seus primeiros registros no norte e no nordeste já na primeira metade do século XIX (Cavalcanti 2000): Bumba-meu-boi no Maranhão e no Piauí; Boi-bumbá no norte do país; Cavalo Marinho na Paraíba; Boi de calemba no Rio Grande do Norte; Boi pintadinho no Rio de Janeiro; Boi de mamão em Santa Catarina. Na etimologia proposta por Câmara Cascudo (1984:150), “Bumba!" é a forma imperativa do verbo bumbar, que significa dançar ou surrar - uma sobreposição cuja ambivalência de sentidos se faz presente de modo notável nas múltiplas narrativas de origem que acompanham de modo variado as diversas formas 
da brincadeira no país articuladas em torno do bicho mítico que morre e ressuscita (Cavalcanti 2006b).

No festival dos Bumbás de Parintins, o "boi" pode ser compreendido como um símbolo dominante, fator decisivo da ação social em torno do qual os múltiplos planos da brincadeira se articulam e que condensa em si diferentes níveis de sentido (Turner 2005a; Cavalcanti 2012b). Ao bicho mítico que morre e ressuscita nas narrativas de origem podemos ligar as duas agremiações, elas mesmas autodenominadas Bois, que desejam sempre ressurgir do esgotamento de sua vitória ou derrota em um ano e reviver num novo confronto festivo. Boi emblema dos grupos, simbolizado em miniaturas, desenhos e muitas imagens estampadas em camisetas, paredes e bandeirolas que se espalham pelas lojas e ruas da cidade. Aos atributos do boi mítico podemos vincular também as características de força, resistência e potência expressas tanto nos antigos e violentos enfrentamentos de rua como no ethos afirmativo da acentuada rivalidade que organiza a festa atual. Porém, na dimensão mais concreta da brincadeira, é para o boi-artefato em ação ritual que convergem os sentimentos de apreço profundo e de carinho devotados pelos brincantes a seu "Boi".

Nos ensaios e nas saídas de rua, nas performances festivas nas comemorações de vitória ou de derrota após o anúncio dos resultados do julgamento anual, o comparecimento do boi dançante é cercado de especial atenção e emoção. Nas performances, sua principal ação ritual é uma exímia dança - a um só tempo vigorosa, ágil e graciosa, executada graças ao talento do tripa - o bailarino que se enfia dentro da carcaça do bicho inteiramente adaptada a seu corpo. Em Parintins, esse boi-artefato bailante ganha o mesmo nome do grupo: Boi Caprichoso ou Boi Garantido, nomes idênticos ao das duas agremiações rivais. Esse boi bailante é o objeto-foco de intensa transposição afetiva e a exegese nativa nos diz que uma pessoa sabe realmente qual é o seu Boi quando se comove intimamente com a dança de um deles:

O boi cujo corpo preto traz na testa uma estrela azul, as cores da agremiação Boi Caprichoso, num binarismo em que azul é o marcado e preto, o não marcado.

O boi de corpo branco que traz na testa um coração vermelho, as cores da agremiação Boi Garantido, num binarismo em que vermelho é o termo marcado e branco, o não marcado.

A partir do que se produz de modo recorrente entre os brincantes a seguinte cadeia de associações: Caprichoso $=$ azul + preto + estrela na testa $=$ intelecto $=$ frio $=$ pessoas frias, sensatas, compreensivas; ou ainda Garantido $=$ vermelho + branco + coração na testa $=$ passionalidade $=$ quente $=$ pessoas quentes, passionais e expansivas. 
Essa exegese, assim expressa, me foi apresentada em conversa mais demorada em junho de 1999 por Odineia Andrade, professora parintinense, antiga brincante do Boi Caprichoso e pesquisadora local dos Bumbás. Pude confirmá-la inúmeras vezes, emitida com variações por brincantes de ambos os grupos. A dez dias da festa, em junho de 2010, em um churrasco organizado por um grupo de jovens torcedores do Boi Caprichoso, Juliana, manauara e assídua torcedora, me explicava a diferença entre eles e "a galera do boi contrário". Galera é o termo nativo que designa a organização dos torcedores dos dois Bois de Parintins ${ }^{7}$. Segundo, ela, a galera do Garantido "não se importa em dançar e cantar independentemente de o seu boi estar bom ou não. Depois dizem que a gente é fraco! Mas não é não. Somos apaixonados. O Caprichoso é exigente, perfeccionista, quer fazer o melhor. Isso é que é amor! A nossa galera, por isso, é um termômetro da qualidade do nosso boi!".

A explicação tem como pano de fundo a forma diversa de expressão dos próprios torcedores de cada boi durante as performances de seus respectivos bois na arena. Esses torcedores, reunidos nas arquibancadas em "galeras" opostas, dançam sempre animadamente durante a apresentação de seu Boi, em especial durante as toadas ditas de "animação" que solicitam sua manifestação explícita. Em ambas, também, essa dança coreografada é sempre acompanhada de muitos adereços que produzem notáveis efeitos visuais. No entanto, a galera do Boi Garantido é famosa por fazer as arquibancadas do estádio tremerem durante sua dança. A galera do Boi Caprichoso, por sua vez, deriva sua fama não apenas de sua animação dançante, mas também do seu esmero nas coreografias e nas alegorias.

Uma grande parte da apaixonada adesão a um ou outro Boi se constrói certamente em função da dedicação, do talento e do envolvimento dos artífices do espetáculo e dos brincantes e torcedores de modo geral, sempre decisivos para o sucesso das performances. Porém, uma outra parte significativa dessa adesão apaixonada constrói-se e expressa-se por meio das interdições rituais que produzem e exacerbam a rivalidade mútua entre os dois Bois. Tais tabus, que obrigam os adeptos de cada Boi à sua observância na conduta pública, têm o notável efeito de tornar a adesão verificável no espaço urbano de Parintins.

\section{O festival, a catedral e a cidade}

Embora as próprias narrativas históricas sejam objeto de disputa, manipulações e constante reinvenções por parte dos Bois, há certo consenso 
quanto a seu surgimento na segunda década do século XX em bairros que polarizavam contrastes importantes na composição social da cidade de então e em sua topografia urbana. O Boi Garantido teria surgido primeiro na "baixa do São José", uma área situada a oeste da cidade, onde o terreno se afunda e se aproxima do rio; um bairro de extração social mais pobre (pescadores, agricultores, vaqueiros, peixeiros, estivadores). O Boi Caprichoso, composto a partir de extratos médios e mais abastados (comerciantes, professores e fazendeiros), surgiu pouco depois no bairro de Palmares, vizinho ao centro do antigo núcleo urbano, situado a leste da cidade, uma área em que o terreno se eleva suavemente até formar um pequeno monte com escarpas que beiram o rio. Os dois Bois saíam às ruas e confrontavam-se em toadas de desafio, ou mesmo brigando seriamente quando se encontravam.

A memória oral relembra outros Bois, porém apenas Garantido e Caprichoso permaneceram. A acentuada rivalidade mútua parece ter dado forma e expressão ritual a oposições importantes na topografia e na morfologia urbanas. Entretanto, a referência para o deslocamento rotineiro dos citadinos não é a topografia, mas o curso do rio, e quem caminha para o leste/jusante vai "para baixo", em direção a Santarém, e quem vai para o oeste/montante, vai "para cima", em direção a Manaus. "Vamos dar uma pernada para cima?" - foi assim, em junho de 1999, com o convite informal de um artista do Boi Caprichoso para uma caminhada até o curral do Boi Garantido, que me dei conta da relevância do curso do rio Amazonas como referência de orientação dos parintinenses. Curiosamente, a evolução da composição social dos dois grupos é também compensatória, pois o grupo de origem "baixa" caminhou para cima e aquele de origem "alta" caminhou para baixo, no sentido em que, ao longo de décadas, a expansão de ambos incluiu todos os extratos sociais urbanos de seus bairros, centro e arredores, expandindo-se, em especial já nos anos 1980, para a capital do estado, Manaus, para onde já haviam migrado ao longo do século XX muitas famílias parintinenses.

O Festival folclórico foi criado em 1966 por um grupo da Juventude Católica na quadra da futura catedral da padroeira da cidade, Nossa Senhora do Carmo, na antiga Praça do cemitério, situada entre os dois bairros de origem dos Bois. O festival durava dez dias e o foco das apresentações eram então as quadrilhas juninas dos bairros mais periféricos. Os Bois eram atração secundária, apresentando-se apenas para encerrar o festival, em intervalos temporais afastados, de modo a evitar o perigo de seus encontros. Entretanto, sua apresentação livre no primeiro festival logo se tornou disputa, pois a adesão dos moradores conformou duas torcidas, e trouxe os Bois para o centro da cena. 
Essa maneira de compreender a evolução da festa me foi proposta por participantes de ambos os grupos ${ }^{8}$. A ela devem se acrescentar importantes alterações ocorridas na organização social do espaço urbano entre o primeiro festival, de 1966, e a inauguração do próprio "Bumbódromo", o estádio Amazonino Mendes, em 1988.

Esse primeiro Festival folclórico visava também angariar fundos para a construção da catedral, iniciada nos anos 1960 e finalizada apenas em meados dos anos 1980. Para lá foi transferida a imagem da padroeira da cidade, Nossa Senhora do Carmo, antes abrigada em uma igreja situada a leste. A confluência desses dois processos - a criação e o sucesso do Festival folclórico e a construção da Catedral de Nossa Sra. do Carmo - configurou gradualmente um novo centro urbano, que substituiu o antigo, hoje o chamado centro histórico, situado a leste da ilha. Organizou-se então na cidade um novo eixo integrador de duas metades territoriais. A tradicional rivalidade dos Bois assumiu dimensão inédita: doravante não eram mais apenas Caprichoso e Garantido - ambos, por sinal devotos da padroeira - mas "Os Bumbás de Parintins". Já nos anos 1970, os Bumbás iniciaram sua expansão rumo à capital do estado, transformando-se em Associações civis, realizando ensaios e saídas nas ruas de Manaus. O Festival folclórico associou-se fortemente à representação da própria cidade.

Nesse novo contexto, a localização do atual Bumbódromo, inaugurado em 1988 e situado no terreno de um antigo aeroporto, integrou uma nova dinâmica urbana. O estádio traça, juntamente com o cemitério local, a catedral, o mercado municipal e o porto, uma linha imaginária, que divide a cidade em uma metade leste e outra metade oeste. Em Parintins, para usarmos termos de Lévi-Strauss (1967), superpõem-se duas estruturas relacionais. Uma concêntrica e hierárquica, que iguala todos diante de certas instâncias superiores - o Festival folclórico, a santa padroeira, o cemitério, a prefeitura, o governo do estado, os patrocinadores da festa, o comércio e o contato dos ilhéus com as demais cidades da região, e com a capital. Outra, diametral, pois, quando o assunto é Boi, tudo na cidade divide-se em dois.

A arena do estádio festivo é cercada por assentos divididos em cadeiras numeradas em sua parte inferior e em arquibancadas na parte superior. Depois de uma reforma em 2013, o conjunto do estádio comporta 16,5 mil lugares $^{9}$. Pintados em vermelho ou azul, todos os assentos dividem-se na metade oeste, pertencente aos torcedores do Boi Garantido; e na metade leste, pertencente aos torcedores do Boi Caprichoso. Os torcedores jovens, organizados em "galeras", ocupam as arquibancadas laterais que abrigam, cada uma, cerca de 3.750 lugares. Esses lugares das Galeras são gratuitos e 
seu preenchimento é autorregulado. De frente para os portais de entrada dos Bois na arena, divididos por um amplo telão para a transmissão televisiva simultânea, situam-se ao fundo do estádio duas fatias de arquibancadas com assentos disponíveis para a compra, também devidamente coloridas conforme a sua respectiva metade. Tudo se distribui de tal modo que os únicos lugares neutros para a participação do expectador no festival são as cabines dos atualmente 11 jurados distribuídos em cinco pontos do estádio ${ }^{10}$ e os lugares destinados à imprensa e ao televisionamento. A própria arena divide-se em metades virtuais contíguas às metades do traçado urbano, e pode ser pensada como uma metonímia da totalidade da cidade. Em 1996, em suas dependências no Galpão do Boi, Marquinho, o tripa do Boi Caprichoso, me dizia: "quando piso na arena, sinto subir uma força do chão. E me protejo com o terço, pois bem ali, na metade da arena, tem a energia positiva e negativa dividida em dois [...]".

Fora do Bumbódromo, a oeste, ou para "cima" (no baixo) fica o Boi Garantido, seu Curral, a quadra de ensaios, e seu Galpão, a oficina de confecção de alegorias. No lado leste, ou para "baixo" (no alto), fica o Boi Caprichoso, seus Curral e Galpão. De tal modo que, ainda hoje, caminhar para "cima" (oeste/montante) ou para "baixo" (leste/jusante) nas ruas de Parintins é adentrar a rede de relações de um dos Bois Bumbás. No período festivo, essa circulação não é inteiramente livre.

\section{As interdições, a espionagem e a provocação}

A organização da festa a cada ano se inicia logo no segundo semestre do ano anterior, entre agosto/setembro, com a definição do novo tema-título, e com o início do concurso das toadas que, como me disse Gil Gonçalves, radialista e diretor de arte do Boi Caprichoso em 2010, "vão na frente", "chamam as pessoas", "aquecem o Boi". Os diversos preparativos se iniciam e se prolongam pelos primeiros meses do ano seguinte. Já no começo de junho, o ambiente festivo se instala em Parintins e, a partir de 23 de junho, Dia de São João, quando os dois Bois atualmente saem às ruas (cada um em seu próprio percurso), a festa toma conta da cidade com a instalação de feiras de artesanato na Praça da catedral e de muitas barracas de comida nas principais vias. Nesse período, dois conjuntos de interdições e duas práticas propiciatórias participam de modo notável da instauração do ambiente festivo no espaço público, e seu gradual agravamento anuncia e prepara as performances na arena: a interdição das cores e as interdições semânticas; e a espionagem e as provocações. 


\section{A interdição das cores}

A interdição de uso das cores do Boi contrário é uma regra geral do Boi e associa-se à lógica de uso e definição do espaço urbano pouco a pouco demarcado em territórios de pertencimento. Certos lugares e seus arredores são "quentes", ou seja, tornam-se territórios azuis ou vermelhos, não simplesmente pelo uso das cores do grupo, mas sobretudo pela proibição de uso da cor do contrário. A interdição é genérica: atinge qualquer um que entre nesses locais, não simplesmente brincantes ou artistas do Boi. Entrar em qualquer domínio do Boi vermelho requer a abstenção de uso da cor azul e vice-versa. As tonalidades respectivas são também contraindicadas; a infração pode implicar o pedido de retirada, ou gerar constrangimento nos anfitriões e, no infrator, o sentimento de faltar a uma regra de etiqueta elementar.

A interdição vigora por definição em todos os locais e espaços rituais de cada Boi - dos ensaios nos currais e trabalho nos galpões às apresentações na arena - onde o regulamento não só proíbe, como penaliza o uso das cores de um Boi pelo outro. Como cada metade das arquibancadas está pintada com a respectiva cor forte de seu Boi, a multinacional Coca-Cola viu-se obrigada a curvar-se aos valores locais, tornando azul o seu anúncio no setor leste do estádio. Em 1999, a empresa Telemar, cujas cores emblemáticas eram o azul e o branco, foi obrigada a trocar de cor os telefones instalados nas ruas situadas na metade oeste da cidade sob ameaça de depredação. Em 2010, as marcas dos patrocinadores na arena festiva - Nestlé, Kaiser, Coca-Cola, TV Bandeirantes, Secretaria de Cultura e Governo do Estado - coloriram-se todas nas duas cores obrigatórias às respectivas metades da arena.

Com a chegada da festa, os moradores e, em especial, os grupos das torcidas jovens dos Bois, que vêm também das cidades vizinhas - Manaus, Nhamundá, Barreirinha, Maués, Tabatinga, Humaitá, entre outras demarcam seus locais de encontro, decorando as ruas com bandeirolas e pinturas na cor de seu Boi. Instaura-se um circuito de lazer Caprichoso e outro Garantido na cidade: restaurantes, banhos (locais de mergulho no rio e nos igarapés), pontos de encontro nas praças que beiram o rio. Alguns mais fanáticos abolem a cor do adversário da vida doméstica cotidiana.

\section{As interdições semânticas}

A língua e a fala são também territórios vocabulares demarcados por interdições simbólicas. A principal é a de jamais nominar o Boi adversário que é sempre o "contrário". Todas as palavras compostas pelas unidades morfológicas contrárias - caprich e garant - estão também banidas do vocabulário de cada grupo. É uma gafe utilizá-las na presença dos torcedores de um ou 
de outro Boi. A enunciação do nome alheio configura-se como indesejável invasão, pois introduziria, no contexto da fala, a presença concreta do outro. Tal presença é afastada pela interdição que a esvazia de conteúdo. Ao valorar a simples menção do nome, o tabu regra um contato mental impossível de ser evitado, pois que fundante da identidade mútua.

Assim é que, ao iluminar apenas a forma vazia da contrariedade do outro Boi, a categoria nativa "contrário" é altamente instrutiva. Como um grupo é o "contrário" do outro, estabelece-se tácita e mutuamente o reconhecimento de uma equivalência e o princípio relacional de sua unidade. A existência velada do "contrário" remete à razão de meu ser cujo destino é o confronto com ele. Trata-se, então, de tornar os dois Bois o mais divergentes possível, e para tanto tudo dentro de um Boi deve ser feito em absoluto segredo. A espionagem e as provocações complementam essas interdições, buscando transpor seus limites.

\section{Espionagem e provocação}

Certamente é possível encontrar um jovem vestido de vermelho, a cor do Boi Garantido, sozinho, encostado quieto na parede em um ensaio no curral do Caprichoso. Ele ficará lá um pouco, observando, ninguém o incomoda e ele logo se retirará. E vice-versa. É também comum que quem encena algum dos personagens do Boi, como a sinhazinha da fazenda, cunhã poranga (Moça bonita, em tupi) vá "dar uma colocada" no ensaio do contrário. Há amizades entre os jovens torcedores dos dois grupos e as famílias, por vezes, têm seus membros divididos na preferência por um ou outro Boi. Porém, na temporada festiva, é preciso cuidado com as inter-relações, pois a presença ou a proximidade física do outro em ambientes de pertencimento definido pode ser só provocação, mas pode ser também alguma estratégia de espionagem, nunca se sabe ao certo... A suspeita ronda as tentativas de aproximação. Em 2010, um dos chefes de galera do Caprichoso esquivou-se de todas as formas possíveis de nos mostrar (a mim e a Ricardo Barbieri) os kits de adereços para os efeitos especiais e planos de execução coreográfica. Assim também a coordenadora da casa que hospedava os jovens torcedores do Caprichoso vindos de Manaus esquivou-se decididamente de maiores contatos. Quem sabe não seríamos espiões do Boi contrário?

A espionagem é sabidamente praticada por ambos os grupos, motivada pelo desejo de obter para si aquilo que está guardado em segredo pelo outro. Além dos efeitos especiais criados pelas galeras, o roteiro da apresentação das noites de performance com a indicação dos efeitos especiais das alegorias e do surgimento dos personagens é cobiçado. Como pudemos presenciar naquele mesmo ano, o roteiro de apresentação da primeira noite do Caprichoso transformou-se durante a madrugada, pois o livreto que orienta 
o julgamento das apresentações tinha "vazado" na gráfica. O episódio foi impressionante, pois a resposta à espionagem do contrário - que teria então supostamente reorganizado a sua própria apresentação da primeira noite de modo a "copiar" e a superar o outro - envolveu a surpreendente troca (que contrariava o roteiro do livreto àquela altura já entregue aos jurados) de um cenário alegórico por outro que, previsto apenas para a terceira noite da festa, foi concluído pouco antes da performance.

A provocação aberta também faz parte da festa e, nesse caso, as toadas de desafio ocupam lugar singular. A maioria das diversas modalidades de toadas destina-se à dança nos ensaios e na arena, exceto as toadas de desafio. Estas abarcam tanto as agressivas toadas de improviso tiradas pelos Amos dos dois Boi na arena em suas respectivas performances, como as toadas que circulam fora das performances oficiais e se destinam à pura provocação do contrário. Estas últimas são divulgadas por vezes no CD oficial, e provocam contratoadas que se difundem por meio das emissoras de rádio locais, ou em CDs distribuídos informalmente pelos compositores, até que "chegou o festival e não dá mais tempo", como nos disse, em 2010, Alexandre, manauara, técnico em computação, fiscal dos jurados durante as apresentações e atuante torcedor do Caprichoso. Essas toadas de provocação são muito espirituosas, geralmente parodiam a letra das toadas oficiais, são gravadas em estúdio, com a mesma base sonora da toada oficial, e são sempre rebaixadoras do contrário. Comparecem em interações das provocações de rua, quando um grupo invade o circuito de lazer do outro, nos ensaios das coreografias de galera no Bumbódromo, mas especialmente nas passagens de som de cada Boi que antecedem as performances festivas na arena.

Relato brevemente episódios ocorridos em 2010 cujo entrelaçamento traz de modo mais vivo a dinâmica desses enfrentamentos rituais em que os torcedores dos dois grupos, ao se oporem entre si, unem-se a seus Bois. Em 2010, o Boi Caprichoso contratara como levantador de toadas (o cantor que deve "levantar" a atuação do boi na arena e, literalmente, a galera nas arquibancadas ao cantar as toadas de cada noite de performance) David Assayag, que tem uma voz belíssima e que, por muitos anos, ocupara este posto-chave no Boi Garantido. É bem verdade que, no começo de sua carreira, David cantara também no Caprichoso, e nele permanece até os dias de hoje. Entretanto, a troca de agremiação por uma das "estrelas" de um Boi, sempre emblemáticas do próprio grupo, causou comoção entre os adeptos do Boi Garantido e foi assunto para muita provocação nas ruas e ataques e respostas através das toadas de desafio.

O CD oficial do Garantido já trouxera uma dessas toadas que chamava o "povo contrário" de "boi melancia" e ameaçava: na disputa festiva, o boi 
contrário seria "partido ao meio" e revelar-se-ia "vermelho por dentro, vermelho igual melancia". David Assayag gravou em resposta uma paródia dessa toada, intitulada "Boi bege", em que o vitorioso rei Caprichoso expressava sua pena do desespero e choratório (sic.) do contrário, cuja toada estava mesmo boa era "pra enterro e velório". Fora do CD oficial do Garantido, outra toada de desafio foi também composta "A fábula do rouxinol", em que o rouxinol se transformara em urubu traiçoeiro. Dessa vez, David gravara como resposta uma paródia de toada oficial do próprio Boi Caprichoso, "Sentimento Caprichoso", em que afirmava seu "coração azul". O contrário, cantava ele, devia "ter vergonha na cara", pois para ganhar dele no festival era preciso ter "um vozeirão e muita afinação"11.

Nesse ambiente em que já circulavam pelas ruas e pelos rádios da cidade as toadas e as contratoadas, alguns dias antes da festa, jovens torcedores do Caprichoso, com suas camisas nas cores emblemáticas, estavam reunidos num restaurante em uma das principais avenidas da cidade, no lado leste, quando uma dupla de rapazes, um deles fantasiado de David Assayag (que é deficiente visual e usa sempre óculos escuros) e outro caracterizado como um suposto entrevistador televisivo, parou seu bugre vermelho em frente ao restaurante. O carro trazia no capô uma grande cara de boi estilizada na forma de uma melancia e tocava a dita toada na aparelhagem de som, enquanto os rapazes encenavam uma entrevista em que o cantor confessava ser mesmo "um traíra".

Os jovens Caprichosos, visivelmente irritados e alguns contendo o impulso para a briga, foram se retirando aos poucos. Um deles, entretanto, aproximou-se dos dois rapazes Garantidos e pediu para fotografá-los. Aquilo era afinal parte da brincadeira!, disse ele maliciosamente, pois mais tarde pretendia "fazer umas coisinhas com aquela foto...", insinuando alguma zombaria que faria circular nas redes sociais.

Naquele ano, o Boi Caprichoso ganhou a disputa festiva. Nas comemorações de sua vitória no curral, o ator comediante que faz as vezes de Pai Francisco nas performances (o vaqueiro que nas narrativas de origem da brincadeira mata o boi para satisfazer o desejo de sua mulher grávida e é sempre encenado como um palhaço) subiu ao palco caracterizado trazendo nas mãos uma grande melancia partida ao meio, cujos pedaços vermelhos ele abocanhava deliciado ao som das contratoadas do Caprichoso.

\section{As performances rituais}

Já posicionadas em suas respectivas arquibancadas, a atuação das galeras integra decisivamente a produção do espetáculo dos Bumbás, mas 
antes que ele comece as galeras como que aquecem o ambiente para o confronto artístico que logo se iniciará. Nas três noites festivas, as apresentações se iniciam às $21 \mathrm{~h}$. Mas desde as 10 horas da manhã a galera forma longas filas do lado de fora do estádio. No começo da tarde, uma barreira de policiais militares, que farão a revista da entrada, é montada no ponto norte do estádio, separando a leste e a oeste o início das duas filas (Barbieri 2013). Quando os portões finalmente se abrem, por volta das 16h, rapazes e moças da organização das galeras já estão lá dentro, nas rampas de acesso de cada lado, para a distribuição dos kits com os adereços que serão usados para a produção dos efeitos visuais durante o canto e a dança das toadas. Com as arquibancadas da galera completas (3.750 lugares cada uma), por volta das $17 \mathrm{~h}$ começa a passagem de som do primeiro boi a se apresentar naquela noite, sucedida pela do outro ${ }^{12}$.

Chegam também então o Apresentador, o Levantador de toadas, o Amo do boi que participam desse aquecimento festivo caracterizado pelas provocações abertas com o canto das toadas que circularam nas ruas e pela liberdade que a galera do contrário tem para se manifestar com contratoadas, xingamentos e impropérios de toda sorte. Isto antecede o início da performance a cada noite, até que, às $21 \mathrm{~h}$, a contenção imposta pelo regulamento se instala com rigor. Na apresentação - que não é só diante do outro como verdadeiramente para o outro - o segredo, até então mantido a sete chaves, deve virar surpresa. A rivalidade produzida e exacerbada na conduta ganhará a forma de um verdadeiro potlatch artístico, em que cada boi busca a vitória através de um estilo expressivo próprio, condizente com os parâmetros de sua simbolização: O Garantido sempre muito afirmativo e agressivo em uma performance mais solta; o Caprichoso sempre mais moderado em agressividade, com uma performance mais integrada e visualmente elaborada. Afinal, o Garantido garante e o Caprichoso capricha!

Em cada uma das três noites da festa, Caprichoso e Garantido, cada qual com cerca de 3.500 brincantes, revezam-se na arena do Bumbódromo em espetáculos de cerca de duas horas e meia de duração. Em Parintins, a limitação da competição a dois contendores é assim contrabalançada pela grande elaboração interna da performance. Na apresentação de cada noite, mantido o modelo da apresentação, os grupos renovam suas fantasias, carros alegóricos e lendas encenadas.

O núcleo semântico associado à morte e à ressurreição do boi ampliou-se em Parintins, incorporando o ambiente amazônico e a cultura cabocla com suas lendas e criaturas sobrenaturais, as diferentes culturas indígenas regionais, muitas histórias de destruição de grupos antigos e a defesa ecológica da mata. As apresentações anuais ganharam um tema-título (o termo nativo 
é slogan) que, derivado desse universo simbólico regional mais amplo, se desdobra nas três noites de espetáculo. Atualmente, uma noite de performance se organiza em torno de três grandes cenários alegóricos, e a atuação de cada um, incluindo montagem e desmontagem, dura cerca de 45 minutos. Esses cenários funcionam como molduras vivas para as diferentes sequências dramáticas que nelas se desenrolam - em especial Lenda Amazônica (uma lenda regional), Conjunto Folclórico (a lenda do boi) e Ritual (uma lenda indígena de morte e destruição) - em meio às quais dançam as tribos (grupos de dançarinos fantasiados de índios) e os personagens individualizados do Boi (boi, sinhazinha da fazenda, cunhã poranga, pajé).

Em cada sequência dramática sucedem-se eventos que - narrados pelo apresentador e pelo canto das toadas - conduzem a um clímax. A boa apresentação é pontuada por apogeus, e desenvolve-se em direção a uma apoteose alcançada na sequência alegórica final, geralmente o Ritual. A dinâmica é a de preenchimentos apoteóticos e esvaziamentos subsequentes da arena, até que tudo se esvai, para recomeçar nas duas noites seguintes.

Enquanto os bois se alternam no fabuloso espetáculo que se desenrola na arena, uma parte importante de cada Boi estará presente todo o tempo a cada noite: as galeras que, instaladas em suas respectivas metades das arquibancadas, integram a apresentação do próprio Boi, e de outra maneira, também participam daquela do Boi contrário.

Atuando de forma organizada, a galera saúda a chegada de seu Boi, canta e dança incansavelmente com muita garra ao longo de um espetáculo, enquanto executa efeitos visuais especiais. Na hora do espetáculo contrário, ela permanece sentada, em silêncio profundo, sob o risco de perda de pontos no julgamento caso se manifeste. Assim, em uma mesma noite, cada galera experimenta tanto a expansão do pleno pertencimento como uma forma de existência secundária na quietude do opositor tão silencioso quanto crítico em busca de falhas e erros na apresentação do outro.

As alegorias se movimentam e se transformam diante de nossos olhos, trazendo de seu bojo, de modo surpreendente, os principais personagens dançantes do Boi, geralmente o pajé e a cunhã poranga, e o próprio boi com seu tripa. A superposição das toadas, da dança, da atuação da galera e da encenação alegórica produz o efeito de maravilhamento, no sentido atribuído por Stephen Greenblat (1996): a introdução de um momento único e memorável no fluxo da performance, capaz de suspender o sentido do tempo, substituindo-o pela pura intensidade da vivência. Do lado do "meu" Boi, o maravilhamento assemelha-se, de fato, às experiências de natureza extática e de englobamento puro pela emoção a um só tempo estética e amorosa vivida junto com a massa festiva. Do lado do contrário, o mara- 
vilhamento, moderado pela frieza da observação silenciosa, transforma-se num reconhecimento que não deixa de ser uma espécie de vitória daquele que produziu tal efeito: o outro será realmente vencido (e isso independe da vitória ou da derrota oficiais) na medida em que for pego, ele também (o meu contrário!) maravilhando-se com aquilo de que sou capaz: provocar nele emoções estéticas, mesmo que experimentadas na quietude.

A galera silenciosa do Boi contrário presencia a ocupação integral de um espaço que, naquela duração excepcional, é indivisível. Porém, sua presença muda e alerta mantém aceso o sentido do desequilíbrio resultante desse uso do espaço da arena. Como esse espaço, a arena tornada território de ocupação não pode ser definitivamente nem de um nem de outro - pois a realização desse desejo traria consigo o risco de destruição da própria identidade - e tampouco interessa a sua divisão, a solução é alternar. A arena é, a cada turno, inteiramente minha ou sua. A celebração da vitória é humilhação do outro, ou seja, em certo sentido é a celebração da derrota do outro. A isso, o outro, apenas temporariamente derrotado, responde com a afirmação de si, alardeando a firme disposição para um novo enfrentamento, ou seja, paradoxalmente, a celebração da derrota, embora traga inevitavelmente o sabor da frustração, é a celebração de si. O combate festivo logo se renova em sua busca de equilíbrio entre os contendores. Ambos, ao longo dos anos sempre vitoriosos e sempre derrotados, se igualam em sua busca sem fim.

\section{O trabalho do rito}

Bateson, em Naven (2008), estudou processos de identificação cruzados e de cismogênese, processos de gênese da cisão intrínsecos à produção de ethos diferenciados entre os homens e as mulheres iatmul. São processos que tendem à ruptura da relação, tamanha a tensão neles acumulada. Em Parintins, como pude presenciar em 2004 e em 2010, a própria viabilidade do festival se viu por vezes ameaçada pela impossibilidade de acordo entre os Bois acerca dos jurados. Em 2004, até a primeira noite da festa os dois grupos não haviam conseguido chegar a um acordo acerca dos jurados. Com duas horas de atraso e com o estádio lotado em um ambiente de grande perplexidade e expectativas, um comitê julgador foi finalmente improvisado de modo a permitir o início das apresentações. O júri oficial chegou para a segunda noite e as notas dessa primeira noite acabaram sendo abolidas. Em 2010, o presidente do júri foi impugnado durante o julgamento, pois teriam descoberto seu contato próximo com um integrante de um dos dois grupos. O fato gerou uma crise que por pouco não impediu o anúncio dos resultados pela comissão julgadora que, desconsiderando as notas do suspeito impugnado, soube se reorganizar a tempo de encerrar a última e decisiva etapa 
das performances rituais, o anúncio do julgamento. Esse anúncio, também extremamente ritualizado, é feito na tarde do dia seguinte ao encerramento das apresentações, na presença das galeras dos dois Bois acomodadas nas respectivas arquibancadas, com o posicionamento da Polícia Militar em fila perpendicular ao centro da arena a separar os dois lados do estádio de modo a evitar confrontos.

Ao falar das muitas possibilidades de controle das tendências à ruptura da relação, Bateson menciona a cismogênese complementar: aquela em que, com a acentuação da divergência, os membros de cada grupo tornam-se mais e mais dependentes do comportamento dos membros do outro grupo. Em algum momento desse processo, Bateson supõe, um equilíbrio será atingido igualando as forças da dependência às tendências cismogênicas. No caso do Bumbá, a produção ritual da rivalidade entre os dois Bois acentuou a divergência na simbolização do pertencimento, na criatividade dos dispositivos de evitação e provocação, e na elaboração dos diferentes estilos artísticos e expressivos que caracterizam cada Bumbá. Isto produziu também a mais íntima dependência, de tal modo que a necessidade de diferenciação não cessa de se exacerbar em função de tamanho compartilhamento de interesses, valores e objetivos comuns. Esse parece ser o patamar do instável equilíbrio dos Bumbás de Parintins.

Como o sonho que, ao proteger o sono, é trabalho simbólico, dream work nos disse Freud $(1989,1998)$ - no sentido de que transforma um certo tipo de material vivido em outra ordem de material que possibilita o acesso a outra forma de sentido das experiências vividas - o trabalho do rito no Bumbá protege o lugar fundamental da brincadeira no mundo adulto. Uma brincadeira séria que fala de morte, destruições e renascimentos, ligando lendas e mitos amazônicos às narrativas de morte e ressurreição do boi; que custa dinheiro, trabalho, empenho e muita briga.

À dimensão mítica subjacente e à dimensão real evidente sobrepõe-se no Bumbá de Parintins a deliciosa brincadeira propriamente dita, renovada a cada ano: a experiência de ser-por-meio-do-confronto que se comuta imediatamente em ser-por-meio-da-identificação plena, perda desejada de limites e contornos. Como se experimentássemos lugares extremos entre as possibilidades da vinculação social, e um dos extremos fosse logo chamado a limitar o outro, trazendo a alteridade a princípio recusada para dentro da experiência de ser. Pois essa experiência de ser-por-meio-do-confronto é dramatizada nas performances rituais como experiência de plenitudes efêmeras diante do outro silenciado, mas nunca anulado. Sempre atento e ativo, ele, o "contrário", é também, por sua vez, sujeito da experiência de ver o outro fazer exatamente tudo aquilo de que ele também é capaz e, mesmo, 
quem sabe?, mais capaz. É preciso ceder a vez, e tudo se transforma então em desejo profundo de reconhecimento de si pelo outro. A realização plena ainda que passageira - a mais bela performance na arena - é feita para o outro e tem como condição o seu valor de "contrário": o reconhecimento implícito ao seu direito igualmente pleno de ser que funda a brincadeira.

Recebido em 02 de outubro de 2017

Aprovado em 19 de março de 2018

Maria Laura Viveiros de Castro Cavalcanti é professora do Programa de Pós Graduação em Sociologia e Antropologia, Instituto de Filosofia e Ciências Sociais, Universidade Federal do Rio de Janeiro, Rio de Janeiro/RJ, Brasil. E-mail: <cavalcanti.laura@gmail.com> 


\section{Notas}

• Este texto baseia-se na conferência proferida por ocasião de minha promoção à Professora Titular do Departamento de Antropologia Cultural do Instituto de Filosofia e Ciências Sociais da Una iversidade Federal do Rio de Janeiro em maio de 2015. Gostaria de agradecer os comentários então recebidos dos professores Luiz Fernando Dias Duarte, John Dawsey, José Carlos Rodrigues, Lia Machado e Myriam Lins de Barros, e também a meu colega historiador Marcos Veneu com quem compartilhei o argumento apresentado em sua origem. Agradeço ainda aos pareceristas anônimos pelas sugestões recebidas.

1 Acompanho, de perto e de longe, o Bumbá de Parintins desde 1996, tendo realizado pesquisa de campo nos períodos festivos de 1996 e 1997, 2000, 2004 e 2010. Esse material de pesquisa vem sendo sistematizado sob diferentes ângulos ao longo dos anos (Cavalcanti 2000, 2002, 2006b, 2011, 2012a). A análise da produção ritual da rivalidade aqui empreendida baseia-se, entretanto, em material inédito trazido sobretudo pela pesquisa de campo realizada em junho de 2010. Ricardo Barbieri, então recém-mestre e meu ex-aluno, viajou comigo e a ele agradeço a valiosa parceria que me permitiu estar tão à vontade entre os jovens da galera do Boi Caprichoso. Como ficará claro ao leitor, a dinâmica da rivalidade festiva, permeada pelos segredos, as evitações e as provocações que analisaremos, se impõe com força obrigatória ao pesquisador necessariamente inserido em uma ou outra rede de relações dos Bois locais.

2 Sem nenhuma pretensão de exaurir o tema, vale citar entre os clássicos: Bronislaw Malinowski (1976, 1935), Alfred Reginald Radcliffe Brown (1965), Edward Evan Evans-Pritchard (2005, 1978), Max Gluckman (1962), Edmund Leach (1995), Gregory Bateson (2008), Mary Douglas (1976 [1966]), Victor Turner (2005 [1967]), James Peacock (1974), Stanley Tambiah (1985), Clifford Geertz (1973, 1980), Roberto DaMatta (1979), Mariza Peirano (2001), Valério Valeri $(1994,1985)$.

3 Para o detalhamento da etnografia do festival e uma breve história de sua conformação, remeto o leitor a Cavalcanti (2000). O universo das brincadeiras do boi no país elabora com muitas variantes narrativas, não necessariamente encenadas tal e qual nas performances concretas, o tema mítico da morte e ressurreição de um boi precioso. Abordei este assunto em detalhe em Cavalcanti (2006). Para outra abordagem acerca da história do Bumba-meu-boi, ver Braga (2002).

4 A natureza intermitente da pesquisa de campo com o Bumbá de Parintins merece breve nota. Se não pude me beneficiar da clássica situação de imersão prolongada e contínua no campo (como ocorreu tanto na pesquisa do espiritismo kardecista como na do carnaval carioca mencionadas), a extensão temporal desse acompanhamento iniciado em 1996 me permitiu apreender o curso do festival em seus traços mais amplos, com suas transformações e reiterações. Em especial, dada a natureza central da rivalidade na organização do festival, essa intermitência me permitiu experimentar os pontos de vista diversos e complementares dos dois Bois acerca da festa. Embora desde o primeiro momento eu tenha me inserido em uma 
rede de relações do Boi Caprichoso, pude estabelecer contatos relevantes com integrantes do Boi Garantido, em especial em 1999 e em 2004, quando privilegiei a interação em campo com esse Boi, frequentando seu curral e tendo mesmo participado como instrumentista de xeque-xeque de sua batucada numa saída de rua em 1999. E, obviamente, o trabalho de observação e pesquisa mais amplos incorporam os dois Bois. Mantive a maiúscula no substantivo Boi para o grupo ou associação brincante, a minúscula refere-se ao boi-artefato que brinca na arena animado pelo seu tripa, ou de modo geral à brincadeira de boi.

5 Realço a escolha da categoria nativa brincadeira para o enfoque do processo ritual em curso. Proponho justamente articulá-la à categoria brincadeira como conceito analítico. O Bumba-meu-boi em suas diversas variantes já foi recorrentemente classificado na bibliografia dos estudos de folclore, a meu ver equivocadamente como um auto popular (ver Cavalcanti 2006b e Carvalho 2011). Nos anos 1950 e 1960, no contexto das pesquisas incentivadas pelo Movimento Folclórico Brasileiro (ver Vilhena 1997), foi classificado como um "folguedo", termo com o qual se pretendia captar a natureza dinâmica e artisticamente rica das expressões folclóricas encontradas no país. Antes disso, Mário de Andrade inseriu-o em sua complexa conceituação das danças dramáticas brasileiras (Andrade 1982). Para uma avaliação crítica da noção de dança dramática, ver Cavalcanti (2004).

6 A natureza mítica de todo o universo de variantes da brincadeira do boi elaborada narrativamente em torno do tema da morte e ressurreição de um boi precioso é notável e abordei-a em detalhes discutindo sua relação com as performances rituais em Cavalcanti (2006b). Sumarizo minha variante de referência: Um boi precioso, forte e potente foi adquirido por um rico fazendeiro como presente para sua filha e entregue aos cuidados do vaqueiro de sua especial confiança. A mulher do vaqueiro estava grávida e desejou comer a língua desse boi. Dilacerado entre lealdades, o vaqueiro termina por matar o boi para satisfazer o desejo da esposa. Descoberto o "crime", índios saem à procura do casal e o trazem à presença do fazendeiro, que o perdoará caso o boi ressuscite. Um médico e um padre tentam fazê-lo sem sucesso e finalmente um pajé o consegue. Todos celebram em festa.

7 O termo galera parece inspirar-se nas "galeras" do funk do Rio de Janeiro, entretanto seu tipo de organização assemelha-se mais ao das torcidas organizadas do futebol, reunindo jovens de proveniência social heterogênea na faixa dos 13 aos 25 anos de idade. Para um estudo das galeras de Parintins, ver Barbieri (2013).

8 Como Raimundo Muniz, integrante do Boi Caprichoso, membro do grupo da Juventude Católica que organizou o primeiro festival folclórico, entrevistado em 1999; e Jair Mendes, antigo artista e inovador do Boi Garantido, que trabalhara como aderecista no Cacique de Ramos no Rio de Janeiro no início dos anos 1970, e como artista também no carnaval das escolas de samba de Manaus, entrevistado naquele mesmo ano.

9 Essa reforma ampliou apenas os lugares das chamadas cadeiras numeradas, situadas na parte mais próxima de toda a arena e cujos ingressos são vendidos ou doados para os torcedores dos dois Bois. 
10 São 21 os itens de julgamento do Bumbá: apresentador, levantador de toadas, batucada ou marujada, ritual indígena, porta-estandarte, amo do boi, sinhazinha da fazenda, rainha do folclore, cunhã-poranga, boi-bumbá (evolução), toada (letra e música), pajé, tribos indígenas, tuxauas, figura típica regional, alegorias, lenda amazônica, vaqueirada, galera, coreografia, organização do conjunto folclórico. Analisei a dinâmica das apresentações em Cavalcanti $(2000,2002)$. Independentemente da vitória ou da derrota, a distribuição de verbas de patrocínio entre os dois Bois é a mesma. O vencedor recebe o troféu daquele ano. O julgamento merece uma análise à parte para além dos limites deste trabalho. Se todo julgamento em competições festivas da cultura popular é inevitavelmente um foco de tensões, no Bumbá de Parintins isto é levado ao paroxismo, em função da convicção dos brincantes da inevitável adesão a um ou outro Boi de quem quer que com eles entre em contato. Dada a complexidade deste aspecto, limito-me a indicar que o sorteio dos três estados brasileiros de onde advirão os jurados a cada ano ocorre nas vésperas da festa, e a "caça" (expressão nativa) aos jurados inicia-se apenas depois disso. Os estados da região Norte do país estão excluídos do sorteio. Os jurados chegam a Parintins no próprio dia da festa, hospedam-se em local afastado do centro urbano e são permanentemente acompanhados por fiscais dos dois grupos. As suspeitas rondam o ambiente e as impugnações são frequentes no limite da inviabilização do espetáculo.

11 A toada "Boi Melancia" foi composta por Fred Goes, a "Boi bege", por Cesar Moraes, a "Fábula do rouxinol", por Emerson Maia, e a resposta do Caprichoso, por David Assayag, Adriano Carraça e Benetti. Esta última toada parodiava a toada oficial "Sentimento caprichoso" composta por Adriano Aguiar, Geovane Bastos e Michael Trindade. O festival tem sido televisionado ao vivo pela Band, suas toadas podem ser encontradas com facilidade no youtube.

12 A ordem da apresentação dos Bois a cada noite é definida por sorteio público na véspera da festa na Praça da Catedral. 


\section{Referências bibliográficas}

ANDRADE, Mário de. 1982. "As danças dramáticas do Brasil". In: Oneida Alvarenga (org.), Danças dramáticas do Brasil. 2. ed. Tomo I. São Paulo: Itatiaia/ Instituto Nacional do Livro/ Fundação Pró-Memória. pp. 23-84.

AUSTIN, John. 1962. How to do things with words. Cambridge: Harvard University Press.

BARBIERI, Ricardo José. 2013. “Etnografia da galera do Caprichoso: simbolismo e sociabilidades entre jovens no Festival de Parintins". Textos Escolhidos de Cultura e Arte Popular, 10(1):63-80.

BATESON, Gregory. 2008. Naven. São Paulo: Edusp. . 1972. "A theory of play and fantasy". In: Steps to an ecology of mind. London/San Francisco/Scranton/ Toronto: Chandler Publishing Company. pp. 177-193.

BAUMAN, Richard. 1977. Verbal art as performance. Prospect Heights, Illinois: Waveland Press.

BRAGA, Sérgio Ivan Gil. 2002. Os bumbás de Parintins. Rio de Janeiro: Funarte.

CÂMARA CASCUDO, Luis da. 1984. "Bumba-meu-boi". In: Dicionário do folclore brasileiro. $5^{\mathrm{a}}$ ed. Belo Horizonte: Ed. Itatiaia. pp. 150-154.

CARVALHO, Luciana Gonçalves de. 2011. A graça de contar: um Pai Francisco no bumba-meu-boi do Maranhão. Rio de Janeiro: Ed. Aeroplano.

CAVALCANTI, Maria Laura Viveiros de Castro. 2015. Carnaval, ritual e arte. Rio de Janeiro: Ed. 7 Letras. . 2013. "Drama, ritual e performance em Victor Turner". Sociologia \& Antropologia, 3(2):411-440. . 2012a. "Formas do efêmero. Alegorias em performances rituais". Ilha, 13:163-184.
. 2012b. "Luzes e sombras no dia social. O símbolo ritual em Victor Turner". Horizontes Antropológicos, 37:103-131.

. 2011. "Alegorias em ação". Sociologia \& Antropologia, 1(1):233-249. . 2008. "Drama social: notas sobre um tema de Victor Turner". Cadernos de Campo, 16:127-138.

. 2006a [1994]. Carnaval carioca: dos bastidores ao desfile. Rio de Janeiro: Ed. UFRJ. Revista e ampliada. . 2006b. "Tema e variantes do mito: sobre a morte e ressurreição do boi". Mana. Estudos de Antropologia Social, 12(1):69-104.

. 2004. "Cultura popular e sensibilidade romântica. As danças dramáticas de Mário de Andrade". Revista Brasileira de Ciências Sociais, 19(54):57-78. . 2002. "Os sentidos no espetáculo". Revista de Antropologia, 45(1):37-89. . 2000. "O boi-bumbá de Parintins: breve história e etnografia da festa". História, ciência e saúde. Visões da Amazônia, VI(número especial):1019-1046.

. 1983. O mundo invisível: cosmologia, sistema ritual e noção da pessoa no Espiritismo. Rio de Janeiro: Zahar Ed.

DAMATTA, Roberto. 1979. Carnavais, malandros e heróis. Para uma sociologia do dilema brasileiro. Rio de Janeiro: Zahar Ed.

DAWSEY, John Cowart. 2005. "Victor Turner e a antropologia da experiência". Cadernos de Campo, 13/14:163176.

DOUGLAS, Mary. 1976 [1966]. Pureza e perigo. São Paulo: Ed Perspectiva.

DILTHEY, Wilhem. 2010. "A formação do mundo histórico nas ciências do espírito". In: Filosofia e educação. 
Edição organizada por Maria Nazaré de Camargo Pacheco Amaral. São Paulo: Edusp. pp. 139-236.

DUKHEIM, Émile. 1996 [1912]. As formas elementares da vida religiosa. São Paulo: Martins Fontes.

EVANS-PRITCHARD, Edward Evans. 2014 [1928]. "A dança". In: Maria Laura V.C. Cavalcanti (org.), Ritual e performance. 4 estudos clássicos. Rio de Janeiro: Ed. 7 Letras. pp. 21-38. . 2005 [1976]. Bruxaria, oráculos e magia entre os Azande. Edição resumida. Introdução por Eva Gillies. Rio de Janeiro: Jorge Zahar Editor. 1978. Antropologia social da religião. Rio de Janeiro: Editora Campus.

FRAZER, James. 1981. The golden bough. New York: Gramercy Books.

FREUD, Sigmund. 1989 [1901]. On dreams. New York, London: W.W. Norton \& Company. . 1998 [1900]. The interpretation of dreams. New York: Bard/ Avon Books.

GEERTZ, Clifford. 1997. O saber local. Petrópolis: Vozes.

.1980. Negara. The Theatre State in nineteenth century Bali. Princeton: Princeton University Press. . 1973. The interpretation of cultures. New York: Basic Books.

GLUCKMAN, Max. 1962. Essays on the ritual of social relations. Manchester: Manchester University Press. . 2011 [1963]. "Ritos de rebelião no Sudeste da África". Cadernos de Antropologia. Série Tradução 03. Brasília: DAN/UnB.

GREEN, André. 1982. O discurso vivo. Uma teoria psicanalítica do afeto. Rio de Janeiro: Francisco Alves.

GREENBLAT, Stephen. 1996. Possessões maravilhosas. São Paulo: Edusp.

GUMBRECHT, Hans Ulrich. 2006. In praise of athletic beauty. Cambridge/MA \& London: Harvard University Press.
HARRISON, Jane E. 1908. Prolegomena to the study of greek religion. 2. ed. Cambridge: Cambridge University Press. Preservation Photo copy, 1991. Book Lab. Inc.

KUPER, Hilda. 2014 [1944]. "Um ritual de realeza entre os suazi". In: Maria Laura V.C. Cavalcanti (org.), Ritual e performance. 4 estudos clássicos. Rio de Janeiro: Ed. 7 Letras. pp. 59-101.

LEACH, Edmund. 1995 [1954]. Sistemas políticos da Alta Birmânia. São Paulo: Edusp. .1978. Cultura e comunicação. Rio de Janeiro: Zahar.

LEIRIS, Michel. 1989. La possession et ses aspects théatraux chez les Ethiopiens de Gondar. Paris: Fata Morgana. . 2001. Espelho de tauromaquia. São Paulo: Cosac \& Naify.

LÉVI-STRAUSS, Claude. 1967. "As organizações dualistas existem?". In: Antropologia estrutural. Rio de Janeiro: Tempo Brasileiro. pp. 155-189.

MALINOWSKI, Bronislaw. 1976. Argonautas do Pacífico ocidental. Coleção Os Pensadores. Vol. XLIII. São Paulo: Abril Cultural.

. 1935. Coral gardens and their magic. A study of the methods of tilling the soil and of agricultural rites in the Trobriand Islands. London: George Allen \& Unwin Ltda.

MAUSS, Marcel. 2003a [1923-24]. “Ensaio sobre a dádiva". In: Sociologia e antropologia. São Paulo: Cosac \& Naify. pp. 183-314.

. 2003b. "As técnicas do corpo". In: Sociologia e antropologia. São Paulo: Cosac \& Naify. pp. 401-422. . 2009 [1921]. "A expressão obrigatória dos sentimentos". In: Ensaios de sociologia. São Paulo: Ed. Perspectiva. pp. 325-332.

MERLEAU-PONTY, Maurice. 1964. L'oeil et l'esprit. Paris: Éditions 
Gallimard.

PEACOCK, James. 1974. Rites of modernization: symbols and social aspects of Indonesian proletarian drama. Chicago/London: The University of Chicago Press.

PEIRANO, Mariza (org.). 2001. O dito e o feito. Ensaios de antropologia dos rituais. Rio de Janeiro: Relumé Dumará.

RADCLIFFE-BROWN, Alfred Reginald. 1965 [1932]. The Andamam islanders. Chicago: University of Chicago/ The Free Press. . 1973. Estrutura e função na sociedade primitiva. Petrópolis: Vozes.

SEVERI, Carlo. 2007. Le principe de la chimère: une anthropologie de la mémoire. Paris: Presses de l'Ecole Normale Supérieure / Musée du Quai Branly.

SIMMEL, George. 1971. "Forms of social Interaction". In: On individuality and social forms. Selected writings (Ed. Donald Levine). Chicago and London: The University of Chicago Press. pp. 41-126.

SKORUPSKY, J. 1976. Symbol and theory. A philosophical study or theories of religion in social anthropology. Cambridge: Cambridge University Press.

SMITH, William Robertson. 2005. Lectures on the religion of the semites. Elibron Classics. [Burnett Lectures 1888-1889]. Boston: Adaman Media Corporation.

TAMBIAH, Stanley. 1985. Culture, thought and social action. An anthropological perspective. Cambridge: Harvard University Press.

TURNER, Victor. 2005a [1967-1965]. “Os símbolos no ritual Ndembu". In: Floresta dos símbolos: aspectos do ritual ndembu. Niterói: EdUFF. pp. 49-94. . 2005b [1967-1964]. "Betwix, between: o período liminar nos ritos de passagem". In: Floresta dos símbolos: aspectos do ritual ndembu. Niterói: EdUFF. pp. 137-158.

TYLOR, Edward Brnett. 1970 [1871]. Primitive culture. Cambridge: Cambridge University Press.

VALENTIN, Andreas. 2005. Contrários. A celebração da rivalidade dos bois-bumbás de Parintins. Manaus: Ed. Valer.

VALERI, Valerio. 1994. "Rito". Enciclopédia Einaudi. Vol. 30. Imprensa Nacional. Casa da Moeda. Lisboa: Ed. Portuguesa. pp. 325-359. .Kinship and sacrifice. Ritual and society in Ancient Hawaii. Chicago and London: The University of Chicago Press.

VAN GENNEP, A. 2011 [1909]. Os ritos de passagem. Petrópolis: Ed. Vozes.

VERNANT, Jean Pierre. 2001. "Formas de crença e de racionalidade na Grécia". In: Entre o mito e a política. São Paulo: Edusp. pp. 197-225.

VILHENA, Luis Rodolfo da Paixão. 1997. Projeto e missão: o Movimento Folclórico Brasileiro. 1947-1964. Rio de Janeiro: Funarte/ Fundação Getúlio Vargas.

WINNICOT, Donald. 1975. O brincar e a realidade. Rio de Janeiro: Imago Ed.

ZUMTHOR, Paul. 1972. Essai de poétique médievale. Paris: Éditions du Seuil.

The epic of Gilgamesh. London: Penguin Epics. 


\section{O RITUAL E A BRINCADEIRA: RIVALIDADE E AFEIÇÃO NO BUMBÁ DE PARINTINS, AMAZONAS}

\section{Resumo}

Este ensaio enfoca a associação, iluminada pela noção de ritual, entre os afetos, a expressão obrigatória dos sentimentos e a experiência social dos grupos envolvidos na produção anual do festival dos Bumbás de Parintins, Amazonas. A noção de ritual, apreendida etnograficamente, conduz a análise da acentuada rivalidade entre os dois grupos de Bumbás que caracteriza o festival e sua preparação. Essa rivalidade é enfocada como uma produção ritual contínua em que a noção nativa de brincadeira ganha especial destaque como laço a unir os dados etnográficos à elaboração conceitual dessa mesma noção - brincadeira - que traz consigo o tema da ambivalência tão característico das trocas agonísticas. A preparação festiva engendra, a partir de inúmeros tabus, evitações, provocações e confrontos, a crescente rivalidade entre os dois grupos brincantes, que se transmuta em expressão artística plena na arena do Bumbódromo. Ali, o almejado esplendor das performances é estimulado pelo desejo obsessivo de superação e derrota do "contrário". O argumento se conclui com a análise do trabalho do rito que, ao produzir abertamente a exacerbação da rivalidade, promove mais silenciosamente a necessária complementariedade e o reconhecimento pleno do outro que funda a possibilidade da brincadeira e torna-a real no ritual festivo.

Palavras-chave: Ritual e simbolismo, Brincadeira, Rivalidade, Afeição, Bumbá de Parintins.

\section{RITUAL AND PLAY: RIVALRY AND AFFECTION IN THE OX DANCE FESTIVAL OF PARINTINS, AMAZONAS}

\begin{abstract}
Taking the notion of ritual as a guideline, this essay focuses on the association between affections, the obligatory expression of feelings and the social experience of the groups involved in the annual production of the Ox Dance festival in Parintins, Amazonas. Apprehended from an ethnographic standpoint, the notion of ritual leads to the analysis of the remarkable rivalry between the two groups of Bumbás that characterizes the festive ambiance. This rivalry is understood as a continuous ritual production and the native notion of play (brincadeira) gains special prominence as a link that unites the ethnographic data to the conceptual elaboration of the very same notion of play which conveys the ambivalence characteristic of agonistic exchanges. The festive preparation generates, by means of innumerable taboos, provocations and confrontations, the growing rivalry between the two playful groups, which transmutes into full artistic expression in the festive arena. There, the soughtafter splendor of the performances is stimulated by the obsessive desire to overcome and defeat the "contrary". The article concludes with an analysis of the rite which, by openly producing the exacerbation of rivalry, surreptitiously promotes the necessary complementarity and full recognition of the other, which establishes the possibility of play and makes it real in the festive ritual.
\end{abstract}

Key words: Ritual and symbolism, Play, Rivalry, Affection, Amazonian Ox Dance Festival. 


\section{EL RITUAL Y EL JUEGO: RIVALIDAD Y AFECTO EN EL BUMBÁ DE PARINTINS, AMAZONAS}

\section{Resumen}

Este ensayo enfoca la asociación, iluminada por la noción de ritual, entre los afectos, la expresión obligatoria de los sentimientos y la experiencia social de los grupos que participan de la producción anual del festival de los Bumbás de Parintins, Amazonas. La noción de ritual, aprehendida etnográficamente, conduce el análisis de la acentuada rivalidad expresa entre los dos Bumbás característica del festival y de su preparación. Esta rivalidad es enfocada como una producción ritual continua en que la noción nativa de juego gana especial destaque como lazo que une los datos etnográficos a la elaboración conceptual de esa misma noción - juego - que trae consigo el tema de la ambivalencia tan característica de los intercambios sociales agonísticos. La preparación festiva produce, a partir de innumerables tabúes, evitaciones, provocaciones y enfrentamientos, la creciente rivalidad entre los dos grupos, que se transmuta en expresión artística plena en la arena del Bumbódromo. Allí, el anhelado esplendor de las performances es estimulado por el deseo obsesivo de superación y derrota del "contrario". El argumento se concluye con el análisis del trabajo ritual que, al producir abiertamente la exacerbación de la rivalidad, aumenta silenciosamente la necesaria complementariedad y el reconocimiento pleno del otro que funda la posibilidad del juego y la vuelve real en el ritual festivo.

Palabras clave: Ritual y simbolismo, Juguetes, Rivalidad, Afección, Bumbá de Parintins. 
